\title{
An unusual case of unilateral supernumerary extensor carpi radialis muscle
}

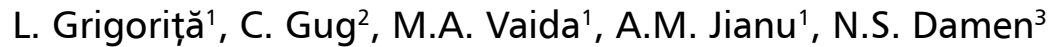 \\ 'Department of Anatomy and Embryology, "Victor Babeş" University of Medicine and Pharmacy, Timisoara, Romania \\ 2Department of Microscopic Morphology, "Victor Babeş" University of Medicine and Pharmacy, Timisoara, Romania \\ 3Paediatric Surgery Clinic of Emergency Children's Hospital, Timisoara, Romania
}

[Received: 8 February 2019; Accepted: 15 March 2019]

\begin{abstract}
An uncommon anatomical variant of muscle that can be considered as a supernumerary extensor carpi radialis muscle was found during the dissection of the forearm region. The identified extensor carpi radialis muscle has origin on the lateral supraepicondylar ridge of the humerus, and an unusual insertion on the tubercle of the scaphoid bone. The presence of this supernumerary muscle may cause diagnostic errors in the forearm region, and can produce a debilitating pain syndrome by secondary compression of adjacent nerves, vessels or tendons due to its course along the anterior compartment of the forearm. (Folia Morphol 2019; 78; 4: 888-892)
\end{abstract}

Key words: supernumerary muscle, forearm, extensor carpi radialis longus muscle

\section{INTRODUCTION}

The posterior compartment of forearm contains in its lateral or radial part three muscles, brachioradialis, extensor carpi radialis longus (ECRL) and extensor carpi radialis brevis (ECRB). Three variants of supernumerary muscles have been described in the literature: extensor carpi radialis intermedius (ECRI) $[3,9,17]$, extensor carpi radialis accessories (ECRA), both describe by Woods [see 3], and extensor carpi radialis tertius (ECRT) [21]. Classically ECRL muscle take origin on the distal third of the lateral supracondylar ridge of the humerus, on the lateral intermuscular septum and on the common extensor origin. The muscle belly continues with a flat tendon which course along lateral surface of the radius, under abductor pollicis longus (APL) and extensor pollicis brevis (EPB), through the second chamber of the extensor retinaculum and insert on radial side of base of the second metacarpal [21]. The variation of ECRL is summarised in Table 1.

Our study supplements the knowledge of muscle variation in the forearm and is of profound interest for the clinician.

\section{CASE REPORT}

During the routine dissection studies for medical students, in the Department of Anatomy and Embryology, "Victor Babeş" University of Medicine and Pharmacy, Timisoara, a unilateral variant of supernumerary muscle was found in a 60 -year-old male formalin-fixed cadaver. During the dissection of the lateral antebrachial regions of the left upper limb, we found an additional belly of muscle, which take origin between the left supraepicondylar ridge, common with the extensor carpi radialis longus and the lateral epicondyle of the humerus, common with extensor carpi radialis brevis, runs craniocaudally between extensor carpi radialis longus and extensor carpi radialis brevis (Fig. 1), and in the middle of the lateral part of the forearm, its tendon cross the tendons of the brachioradialis and ECRL muscles, passing anterior to them, and in relation with the inferior lateral cutaneous nerve of the arm. In contrast to the above mentioned studies, the tendon of the supernumerary muscle had an unusual insertion on the tubercle of the scaphoid bone (Figs. 2, 3). 
Table 1. Variation of extensor carpi radialis longus muscle: a review from the literature

\begin{tabular}{|c|c|c|c|c|}
\hline Cadaver & Author, year & Origin & Tendinous course & Insertion \\
\hline Right and left & $\begin{array}{l}\text { Albright, } \\
1978\end{array}$ & $\begin{array}{l}\text { Additional tendon arising proximally } \\
\text { from ECRL or ECRL tendon bifurcated }\end{array}$ & $\begin{array}{l}\text { On the ulnar side of ECRL } \\
\text { or deep to ECRB tendon }\end{array}$ & $\begin{array}{l}\text { Common insertion with ECRB, } \\
\text { or on the base of the second } \\
\text { metacarpal bone }\end{array}$ \\
\hline Right and left & $\begin{array}{l}\text { Yoshida, } \\
1994\end{array}$ & $\begin{array}{l}\text { Laminar disposition of ECRL } \\
\text { (additional slips) } \\
\text { around a main part }\end{array}$ & $\begin{array}{l}\text { The tendons of additional slips } \\
\text { joined to ECRB or to the main part. } \\
\text { The tendons of the main part and } \\
\text { additional slips may be separated } \\
\text { of each other or fused in the distal end }\end{array}$ & $\begin{array}{l}\text { Main part on the base of second } \\
\text { metacarpal bone. The additional slips } \\
\text { on the first to third metacarpal bones }\end{array}$ \\
\hline Right & $\begin{array}{l}\text { Classen, } \\
2002\end{array}$ & One accessory head & $\begin{array}{l}\text { The tendon passed through a separate } \\
\text { tunnel in the extensor retinaculum }\end{array}$ & $\begin{array}{l}\text { On the middle of the first } \\
\text { metacarpal bone }\end{array}$ \\
\hline Right & $\begin{array}{l}\text { Nayak, } \\
2008\end{array}$ & $\begin{array}{l}\text { Additional muscle with origin } \\
\text { on the common extensor origin }\end{array}$ & $\begin{array}{l}\text { The additional muscle divides below } \\
\text { the abductor pollicis longus }\end{array}$ & $\begin{array}{l}\text { On the base of the second } \\
\text { and third metacarpal bones }\end{array}$ \\
\hline Right & $\begin{array}{l}\text { Prakash Rai, } \\
2008\end{array}$ & $\begin{array}{l}\text { On the lateral supracondylar ridge } \\
\text { of the humerus and on the lateral } \\
\text { intermuscular septum }\end{array}$ & $\begin{array}{l}\text { Muscle belly divided into two tendons } \\
\text { which passed in the second } \\
\text { compartment of extensor retinaculum }\end{array}$ & $\begin{array}{l}\text { On the base of the } \\
\text { second metacarpal }\end{array}$ \\
\hline Right & $\begin{array}{l}\text { Sawant, } \\
2013\end{array}$ & $\begin{array}{l}\text { On the lateral supracondylar ridge } \\
\text { of the humerus and on the lateral } \\
\text { intermuscular septum }\end{array}$ & $\begin{array}{l}\text { Muscle belly dividing into two } \\
\text { tendons, passing in the second } \\
\text { compartment of extensor retinaculum }\end{array}$ & $\begin{array}{l}\text { One tendon into the radial side of the } \\
\text { dorsal surface of the base of the } \\
\text { second metacarpal bone and the } \\
\text { other tendon into the lateral dorsal } \\
\text { surface of the base of the third } \\
\text { metacarpal bone }\end{array}$ \\
\hline Right & $\begin{array}{l}\text { Srimani, } \\
2014\end{array}$ & $\begin{array}{l}\text { Additional belly having common } \\
\text { origin with ECRL }\end{array}$ & $\begin{array}{l}\text { The tendon entered into the second } \\
\text { compartment of extensor retinaculum, } \\
\text { medial to main tendon, but lateral to } \\
\text { ECRB tendon }\end{array}$ & $\begin{array}{l}\text { Into upper and medial aspect } \\
\text { of dorsal surface of base of } \\
\text { second metacarpal bone }\end{array}$ \\
\hline Right & $\begin{array}{l}\text { Yang, } \\
2018\end{array}$ & $\begin{array}{l}\text { On the lateral supracondylar } \\
\text { ridge of the humerus }\end{array}$ & $\begin{array}{c}\text { One muscle belly trifurcated } \\
\text { in three heads, lateral, intermediated } \\
\text { and medial. The medial head } \\
\text { merge with ECRB }\end{array}$ & $\begin{array}{l}\text { The lateral and intermediated heads } \\
\text { on the base of the second metacarpal } \\
\text { bone, the medial head on the base } \\
\text { of the third metacarpal bone }\end{array}$ \\
\hline
\end{tabular}

ECRL — extensor carpi radialis longus; ECRB — extensor carpi radialis brevis

\section{Statement of ethics}

The research was conducted ethically in accordance with The Code of Ethics of the World Medical Association (Declaration of Helsinki).

\section{DISCUSSION}

Extensor carpi radialis longus and the three variants of supernumerary muscles, ECRI, ECRA and ECRT were studied by many researchers [20] using dissection, sonography [7] or by making volumetric-models of extra- and intramuscular innervation [13]. Most of results derived from cadaver studies, with all the limitations of distortion from embalming, positioning and comorbidity [8]. ECRI take origin between ECRB and ECRL $[3,9]$, and inserted on the second or third metacarpal. ECRA originates from the fascia superficial to ECRL and ECRB [3], or as a muscular slip from the belly of ECRL $[1,18]$, or as an additional belly of ECRL $[11,19]$, and inserts on the first metacarpal [3], or into the abductor pollicis longus or abductor pollicis brevis muscles [9]. Classen and Wree [4] described an accessory head of the ECRL which tendon inserted in the middle of the first metacarpal bone. ECRT take origin from the common extensor origin between ECRL and extensor digitorum and inserted on the second and third metacarpal. In the literature (Table 1), were described other variations of ECRL, with normal origin on the lateral supracondylar ridge and then trifurcated in three heads, lateral and intermediated heads with insertion on the base of the second metacarpal bone and medial head with insertion which merge with ECRB muscle [22]. Yoshida [23] describe the muscle bellies of ECRL and ECRB with laminar disposition. Some researchers describe ECRL and ECRB exchanging fleshy or tendinous slips, which can be replaced by distinct muscle [20]. We did not find a classical example of the three variants of supernumerary muscle in our study. Regarding its origin, the supernumerary muscle can be classified as ECRI, or as an additional belly of ECRL, but regarding its insertion, it doesn't belong to this group. 


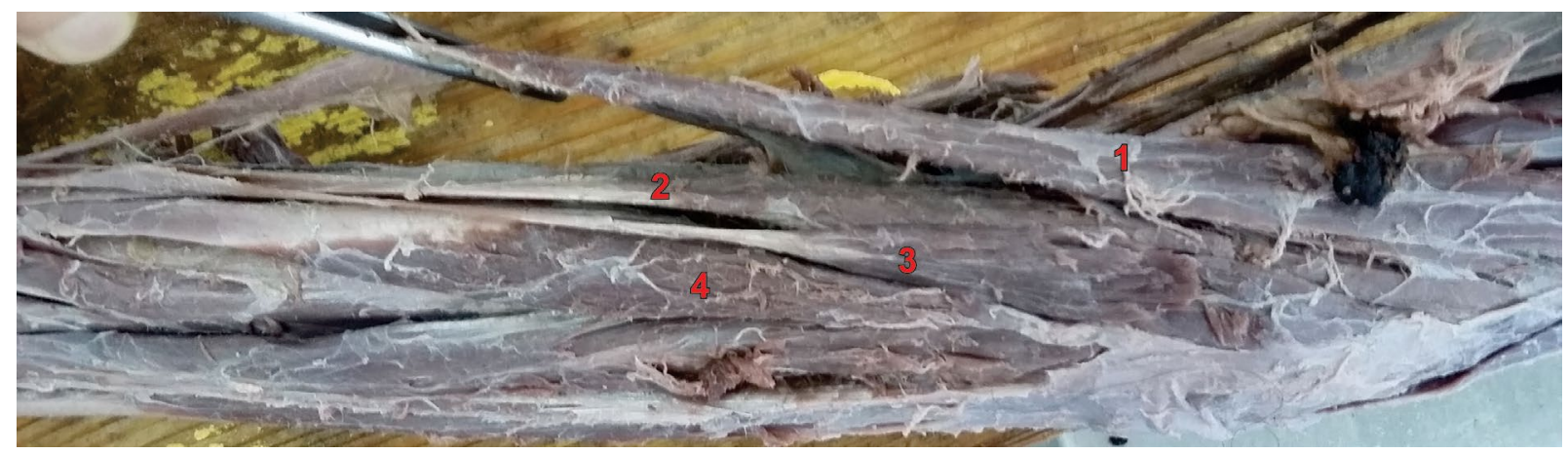

Figure 1. Dissection revealing the brachioradialis muscle (1), the extensor carpi radialis longus muscle (2), the newly found supernumerary extensor carpi radialis muscle (3) and the extensor carpi radialis brevis muscle (4).

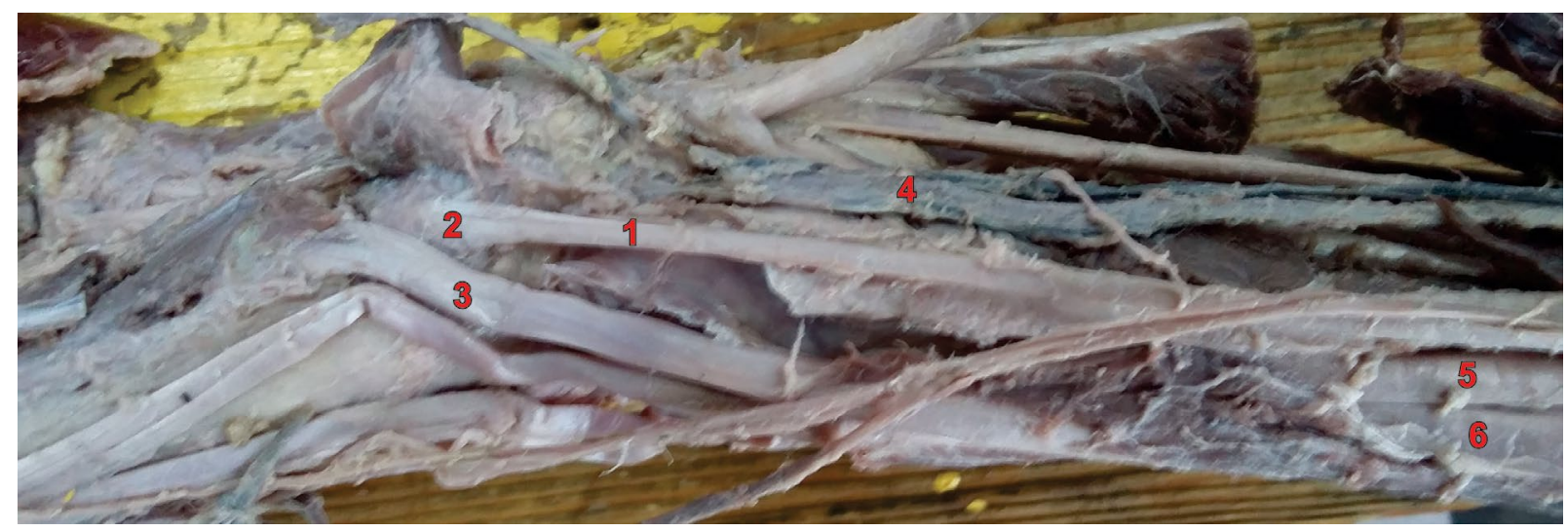

Figure 2. Dissection revealing the newly found supernumerary extensor carpi radialis muscle (1) with its insertion on the tubercle of the scaphoid bone (2), the abductor pollicis longus muscle (3), the radial artery (4), the extensor carpi radialis longus muscle (5) and the extensor carpi radialis brevis muscle (6).

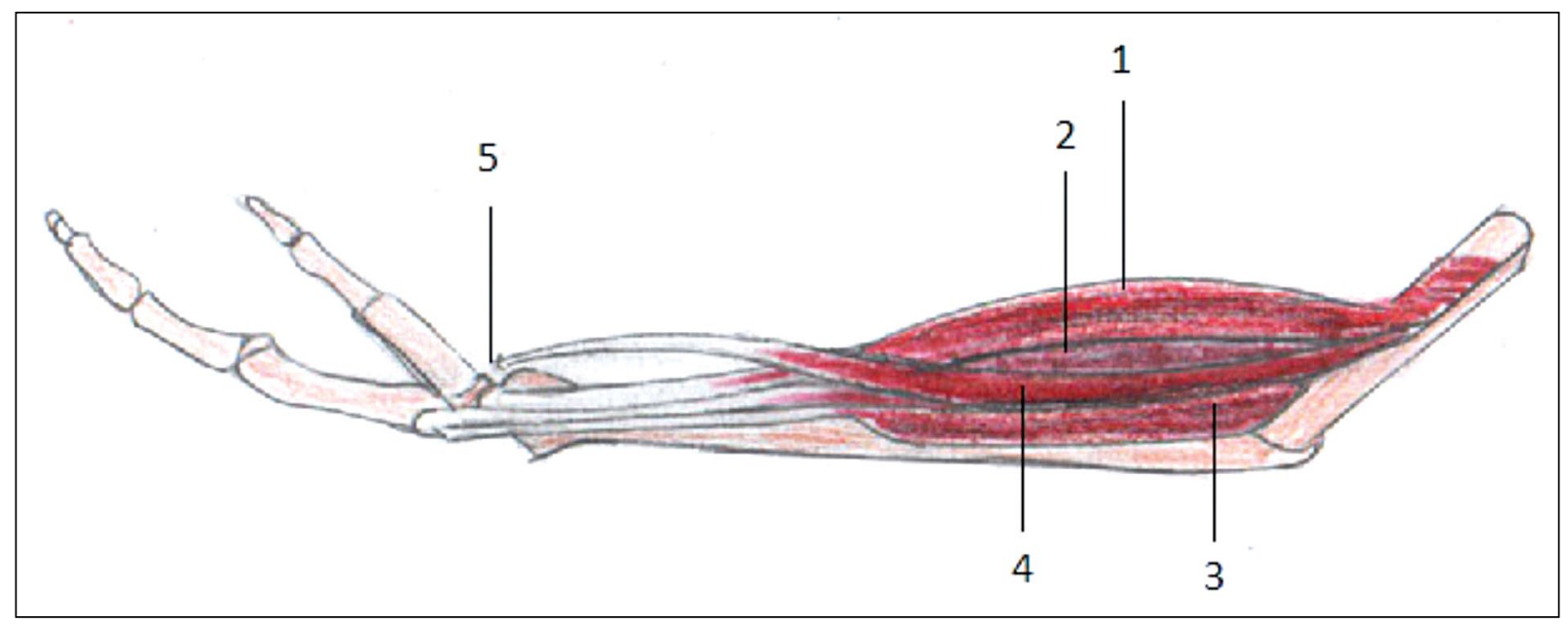

Figure 3. Drawing illustrates the brachioradialis muscle (1), the extensor carpi radialis longus muscle (2), the extensor carpi radialis brevis muscle (3) and the newly found supernumerary extensor carpi radialis muscle (4) with its insertion on the tubercle of the scaphoid bone (5). 
The limb musculature develops from paraxial mesoderm, and in the seventh week of development appears as a condensation of mesenchyme, near the base of the limb buds [15]. With elongation of the limb buds, the muscle tissue splits into flexor and extensor components, which then fuse and form a single muscle mass, so the muscles of the superior limb are composed from tissue derived from several segments, specifically, the lower five cervical and upper two thoracic segments. Under myogenic regulatory factors, some muscle primordia of this muscle mass suffer a cell-death. The persistence of cells not-undergoing into the process of cell-death may explain an additional muscle [17]. Studies made on animals [5], revealed that the ECRL and ECRB muscles differs markedly amongst species in the animal classification system. Cossu and Guintard [5] described two muscles in human, a single muscle in sheep and intermediate states (division in the distal third) in other species, like dog and cat, evolution accompanied by modification of blood supply. In human each muscle is irrigated by a distinct arterial system, in cat two distinct branches for each head of extensor carpi radialis muscle, and in dog and sheep by a single branch from the transverse ulnar artery. Regarding the innervation of ECRL, even when the muscle is separate in two slips, they share the innervation from the radial nerve. In human the three-dimensional modelling study reveal one primary branch from the radial nerve proper divided into anterior and posterior branches, that supplied the superficial and deep region of ECRL muscle belly, so the muscle demonstrate neuromuscular compartmentalisation based on intramuscular innervation [13]. So the presence of a supernumerary muscle can be considered an expression of atavism, and most muscle anomalies are referable to an underexpression of particular developmental factors [2].

These supernumerary muscle bellies of the forearm, especially with unusual insertion can produce a debilitating pain syndrome, secondary to a tendon-muscle shear phenomenon [14] and might misguide the surgeon during surgery and during diagnosis $[6,12]$ and may be useful for reconstruction of hand function in tetraplegic patients $[10,16]$.

\section{CONCLUSIONS}

This rare anatomic variant of extensor carpi radialis muscle, had to be considered by clinicians, because it may cause diagnostic errors in ultrasounds scans or the additional tendon at the wrist may cause a radial tunnel syndrome.

\section{Acknowledgements}

We acknowledge to Mihaela Damen who made the drawing of the present case.

\section{REFERENCES}

1. Albright JA, Linburg RM. Common variations of the radial writs extensors. J Hand Surg Am. 1978; 3(2): 134-138, indexed in Pubmed: 632542.

2. Arey LB. Developmental Anatomy, In: A Textbook and Laboratory Manual of Embryology. Ed. 5. WB Saunders company, Philadelphia 1949: 397-399.

3. Botar J. Sur quelques variations des muscles de l'avant-bras. Bulletins et Mémoires de la Société d'anthropologie de Paris. 1931; 2(1): 25-33, doi: 10.3406/bmsap.1931.9249.

4. Claassen $\mathrm{H}$, Wree A. Multiple variations in the region of $\mathrm{Mm}$. extensores carpi radialis longus and brevis. Ann Anat. 2002; 184(5): 489-491, doi: 10.1016/S09409602(02)80084-X, indexed in Pubmed: 12392329.

5. Cossu F, Guintard C. Anatomical and Descriptive Study of the Radial Extensor Muscle (M. Extensor Carpi Radialis). Anatomia, Histologia, Embryologia: Journal of Veterinary Medicine Series C. 2000; 29(6): 337-343, doi: 10.1046/j.1439-0264.2000.00271.x.

6. Divia Paul A, Gaikwad MR. Additional muscle belly and abberant muscle fibers over the extensor retinaculam of wrist. NUJHS. 2016; 6(1): 85-87.

7. Gitto S, Draghi AG, Draghi F. Sonography of non-neoplastic disorders of the hand and wrist tendons. J Ultrasound Med. 2018; 37(1): 51-68, doi: 10.1002/jum.14313, indexed in Pubmed: 28708327.

8. Hale SJM, Mirjalili SA, Stringer MD. Inconsistencies in surface anatomy: The need for an evidence-based reappraisal. Clin Anat. 2010; 23(8): 922-930, doi: 10.1002/ca.21044, indexed in Pubmed: 20830790.

9. Hong $M K Y$, Hong MKH. An uncommon form of the rare extensor carpi radialis accessorius. Ann Anat. 2005; 187(1): 89-92, doi: 10.1016/j.aanat.2004.08.001, indexed in Pubmed: 15835405.

10. Kerver ALA, Carati L, Eilers PHC, et al. An anatomical study of the ECRL and ECRB: feasibility of developing a preoperative test for evaluating the strength of the individual wrist extensors. J Plast Reconstr Aesthet Surg. 2013; 66(4): 543-550, doi: 10.1016/j.bjps.2012.12.015, indexed in Pubmed: 23369737.

11. Nayak S, Kumar SJM, Krishnamurthy A, et al. An additional radial wrist extensor and its clinical significance. Ann Anat. 2007; 189(3): 283-286, doi: 10.1016/j.aanat.2006.10.005.

12. Rai $R$, Ranade $A$, Prabhu $L$, et al. Multiple variations of extensor muscles of forearm in relation to the radial nerve: a case report and review. Int J Morphol. 2008; 26(2): 447-49, doi: 10.4067/s0717-95022008000200034.

13. Ravichandiran M, Ravichandiran N, Ravichandiran K, et al. Neuromuscular partitioning in the extensor carpi radialis longus and brevis based on intramuscular nerve distribution patterns: A three-dimensional modeling study. Clin Anat. 2012; 25(3): 366-372, doi: 10.1002/ca.21246, indexed in Pubmed: 21853467.

14. Ryu JY, Watson HK. SSMB syndrome. Symptomatic supernumerary muscle belly syndrome. Clin Orthop Relat Res. 1987(216): 195-202, indexed in Pubmed: 3815948. 
15. Sadler TW. Langman's medical embryology. Ed. 13. Williams and Wilkin, Lippincott 2015: 203-206.

16. Sawant SP. The cadaveric study of extensor carpi radialis longus muscle on the developmental basis. Int J Healthcare Biomed Res. 2013; 1(4): 241-245.

17. Smith J, Pourcho AM, Kakar S. Sonographic appearance of the extensor carpi radialis intermedius tendon. PMR. 2015; 7(7): 789-791, doi: 10.1016/j.pmrj.2015.04.005, indexed in Pubmed: 25857593.

18. Sookur PA, Naraghi AM, Bleakney RR, et al. Accessory muscles: anatomy, symptoms, and radiologic evaluation. Radiographics. 2008; 28(2): 481-499, doi: 10.1148/ rg.282075064, indexed in Pubmed: 18349452.

19. Srimani P, Meyur R, De Bo, et al. Unilateral variation of extensor carpi radialis longus muscle: a case report. Int J Anat Var. 2014; 7: 115-117.
20. Tubbs RS, Shoja MM, Loukas M. Bergman's Comprehensive Encyclopedia of Human Anatomic Variation. Wiley-Blackwell 2016: 304-314.

21. West CT, Ricketts D, Brassett C. An anatomical study of additional radial wrist extensors including a unique extensor carpi radialis accessorius. Folia Morphol. 2017; 75(4): 742-747, doi: 10.5603/FM.a2017.0047, indexed in Pubmed: 28553852.

22. Yang K, Choi IJ, Lee JH. Accessory head of the extensor carpi radialis longus muscle merging with extensor carpi radialis brevis muscle. Surg Radiol Anat. 2018; 40(9): 1001-1003, doi: 10.1007/s00276-018-2035-z, indexed in Pubmed: 29713736.

23. Yoshida Y. Anatomical studies on the extensor carpi radialis longus and brevis muscles in Japanese. Okajimas Folia Anat Jpn. 1994; 71(2-3): 127-135, indexed in Pubmed: 7808722. 